\title{
Measured Stark widths and shifts of NII, NIII and NIV spectral lines
}

\author{
V. Milosavljević and S. Djeniže \\ Faculty of Physics, University of Belgrade, P.O. Box 368, 11001 Belgrade, Serbia, Yugoslavia \\ Received March 18; accepted June 18, 1997
}

\begin{abstract}
Stark parameters (widths and shifts) of eight singly, seven doubly and five triply ionized nitrogen spectral lines have been measured in linear pulsed, low pressure, arc discharge in a nitrogen plasma at a $54000 \mathrm{~K}$ electron temperature and a $2.810^{23} \mathrm{~m}^{-3}$ electron density. The measured values have been compared to the existing experimental and calculated data.
\end{abstract}

Key words: lines: profiles-atomic data - methods: laboratory

\section{Introduction}

The abundance of nitrogen in the Earth's atmosphere and, also, the large number of multiply ionized nitrogen spectral lines in hot stars spectra makes these lines of great importance for diagnostics purposes. Knowledge of the Stark width and shift dependence upon the electron temperature $(T)$ in the plasma is, also, of importance for testing their theoretical predictions based on various approaches.

A number of experimental and theoretical papers have dealt with Stark broadening and shift of singly (NII), doubly (NIII) and triply (NIV) ionized nitrogen spectral lines (Fuhr \& Lesage 1993 and references therein; Konjević \& Wiese 1976; Konjević et al. 1984; Konjević \& Wiese 1990). In spite of this, only few publications have been devoted to the experimental and theoretical investigation of the Stark shift values of ionized nitrogen spectral lines. No experimental Stark shift data exists for NIV spectral lines, to the knowledge of the authors.

The aim of this paper is to provide some new data on several Stark shift and width of multiply ionized nitrogen spectral lines at $54000 \mathrm{~K}$ electron temperature. We have measured Stark shifts (d) and Stark HWHM (half-width at half intensity maximum, $w$ ) of eight NII, seven NIII and

Send offprint requests to: S. Djeniže five NIV spectral lines belonging to $3 \mathrm{~s}-3 \mathrm{p}$ and $3 \mathrm{p}-3 \mathrm{~d}$ transitions. Stark shifts of $463.054 \mathrm{~nm}, 464.309 \mathrm{~nm}$ and $399.500 \mathrm{~nm}$ of NII, $486.72 \mathrm{~nm}$ and $486.718 \mathrm{~nm}$ of NIII, as well of $347.87 \mathrm{~nm}, 348.30 \mathrm{~nm}, 348.49 \mathrm{~nm}, 374.77 \mathrm{~nm}$ and $405.78 \mathrm{~nm}$ of NIV spectral lines have not been measured before. The same hold also for the Stark width value of the $348.30 \mathrm{~nm}$ NIV line. Stark shift of the $298.36 \mathrm{~nm}$ spectral line is the first data for the multiplet No. 25UV in NIII spectra. The measured values of Stark widths and shifts were compared to the existing theoretical predictions based on the semi-classical, semi-empirical and modified semi-empirical approaches initiated by Dimitrijević \& Konjević (1980, 1981a,b).

\section{Experiment}

The modified version of the linear low pressure pulsed arc (Djeniže et al. 1991) has been used as a plasma source. A pulsed discharge driven in a quartz discharge tube of $5 \mathrm{~mm}$ inner diameter and has an effective plasma length of $5.8 \mathrm{~cm}$ (Milosavljević 1996). The tube has end-on quartz windows. On the opposite side of the electrodes the glass tube is expanded in order to reduce erosion of the glass wall and also sputtering of the electrode material onto the quartz windows. The working gas is a nitrogen and oxygen mixture $\left(83 \% \mathrm{~N}_{2}+17 \% \mathrm{O}_{2}\right)$ at $70 \mathrm{~Pa}$ filling pressure in flowing regime. Spectroscopic observation of isolated spectral lines is made end-on along the axis of the discharge tube. A capacitor of $14 \mu \mathrm{F}$ is charged up to $3.0 \mathrm{kV}$ and supplied discharge currents up to $7.7 \mathrm{kA}$. The line profiles is recorded by a shot-by-shot technique using a photomultiplier (EMI 9789 QB) and a grating spectrograph (Zeiss PGS-2, reciprocal linear dispersion $0.73 \mathrm{~nm} / \mathrm{mm}$ in the first order) system. The instrumental HWHM of $0.004 \mathrm{~nm}$ is obtained by using of the narrow spectral lines emitted by the hollow cathode discharge. The recorded profile of these lines have been of the Gaussian type within $7 \%$ accuracy in the range of the investigated spectral line wavelengths. The exit slit $(10 \mu \mathrm{m})$ of the spectrograph with the calibrated photomultiplier is micrometrically traversed along the spectral plane in small wavelength steps 


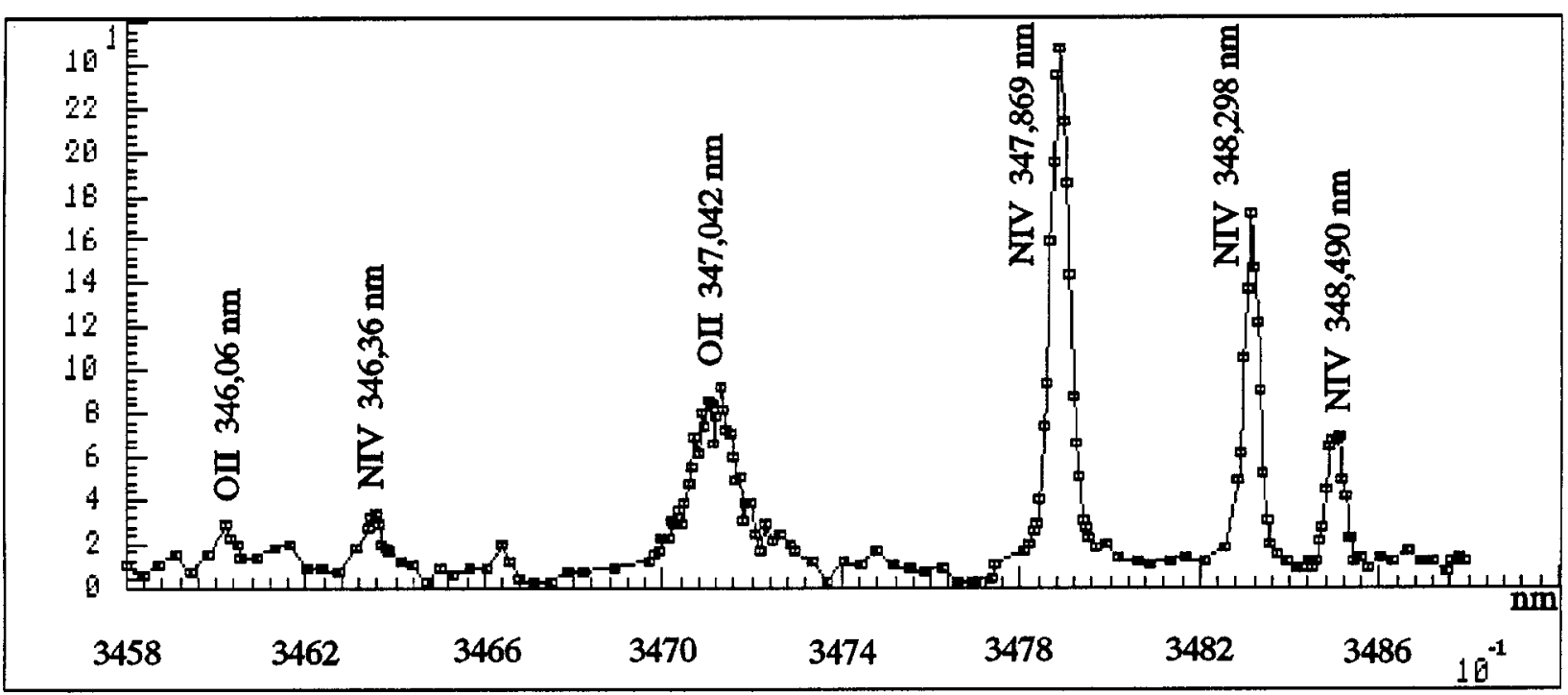

Fig. 1. Recorded spectrum at $11 \mu$ s after the beginning of the discharge (when the spectral line profiles were analyzed) with the investigated NIV spectral lines

$(0.0073 \mathrm{~nm})$. The photomultiplier signal is digitized using an oscilloscope, interfaced to a computer. A sample output, as example, is shown in Fig. 1.

Plasma reproducibility was monitored by the NIII line radiation and also by the discharge current (it was found to be within $8 \%$ ). The measured profiles were of the Voigt type due to the convolution of the Lorentzian Stark and Gaussian profiles caused by Doppler and instrumental broadening. For electron density and temperature obtained in our experiment the Lorentzian fraction in the Voigt profile was dominant (over 80\%). Van der Waals and resonance broadening were estimated to be smaller by more than an order of magnitude in comparison to Stark, Doppler and instrumental broadening. A standard deconvolution procedure (Davies \& Vaughan 1963) was used. The deconvolution procedure was computerized using the least square algorithm. The Stark widths were measured with $\pm 15 \%$ error. Great care was taken to minimize the influence of selfabsorption on Stark width determination. The opacity was checked by measuring line-intensity ratios within multiplets No. 3 in the cases of the NII and NIII spectral lines. The values obtained were compared with calculated ratios of the products of the spontaneous emission probabilities and the corresponding statistical weights of the upper levels of the lines. It turns out that these ratios differed by less than $\pm 14 \%$. The Stark shifts were measured relative to the unshifted spectral lines emitted by the same plasma (Purić \& Konjević 1972). The Stark shift of spectral line can be measured experimentally by evaluating the position of the spectral line centre recorded at two various electron density values during the plasma decay. In principle, the method requires recording of the spectral line profile at the high electron density $\left(N_{1}\right)$ that causes an appreciable shift and then later when the electron concentration has dropped to the value $\left(N_{2}\right)$ lower for at least an order of magnitude. The difference of the line center positions in the two cases is $\Delta d$, so that the shift $d_{1}$ at the higher electron density $N_{1}$ is:

$d_{1}=N_{1} \cdot \Delta d /\left(N_{1}-N_{2}\right)$.

The Stark shift data was corrected for the electron temperature decay (Popović et al. 1992). Stark shift data are determined with $\pm 0.0015 \mathrm{~nm}$ error at a given $N$ and $T$. The plasma parameters were determined using standard diagnostic methods. The electron temperature was determined from the ratios of the relative intensities of the $348.49 \mathrm{~nm}$ NIV to $393.85 \mathrm{~nm}$ NIII and the previous NIII to $399.50 \mathrm{~nm}$ NII spectral lines, assuming the existence of LTE, with an estimated error of $\pm 12 \%$. All the necessary atomic parameters were taken from Wiese et al. (1966). The electron density decay was measured using a single wavelength $\mathrm{He}-\mathrm{Ne}$ laser interferometer (Ashby et al. 1965) for the $632.8 \mathrm{~nm}$ transition with an estimated error of $\pm 7 \%$. Electron temperature and density decays are presented in Fig. 2

\section{Results}

Our experimental results of the measured Stark HWHM $\left(w_{\mathrm{m}}\right)$ and shift $\left(d_{\mathrm{m}}\right)$ values (in $\left.0.1 \mathrm{~nm}\right)$ at $54000 \mathrm{~K}$ electron temperature and $2.810^{23} \mathrm{~m}^{-3}$ electron density are given in the Table 1 together with transition arrays and multiplet numbers

Following ratios $w_{\mathrm{m}} / w_{\text {th }}$ are also given in the same table, where $w_{\text {th }}$ are the existing Stark HWHM values calculated on the basis of various theoretical approximations 
Table 1. Experimental Stark HWHM $\left(w_{\mathrm{m}}\right)$ and shift $\left(d_{\mathrm{m}}\right)$ values (in $0.1 \mathrm{~nm}$ ) at $T=54000 \mathrm{~K}$ electron temperature and $N=2.810^{23} \mathrm{~m}^{-3}$ electron density and those ratios to the calculated Stark width values on the basis of various theoretical approximations: semiempirical (SE), modified semiempirical (SEM) and various modifications of the semiclassical (SC, G and GM) performed by Dimitrijević \& Konjević (1980, 1981a,b) (for details see text). Transitions, wavelengths and multiplets are, also, presented. The positive shift is toward the red

\begin{tabular}{|c|c|c|c|c|c|c|c|c|}
\hline transition & multip. & $\lambda[\mathrm{nm}]$ & $w_{\mathrm{m}}$ & $d_{\mathrm{m}}$ & $w_{\mathrm{m}} / w_{\mathrm{SC}}$ & $w_{\mathrm{m}} / w_{\mathrm{G}}$ & $w_{\mathrm{m}} / w_{\mathrm{GM}}$ & $w_{\mathrm{m}} / w_{\mathrm{SEM}}$ \\
\hline \multirow{8}{*}{$\begin{array}{l}\frac{\mathrm{NII}}{2 \mathrm{p} 3 \mathrm{~s}-} \\
2 \mathrm{p}\left({ }^{2} \mathrm{P}^{0}\right) 3 \mathrm{p}\end{array}$} & \multirow{5}{*}{$\begin{array}{c}{ }^{3} \mathrm{P}^{0}-{ }^{3} \mathrm{D} \\
(3)\end{array}$} & & & & & & & \\
\hline & & 567.956 & 0.380 & -0.01 & - & - & - & - \\
\hline & & 568.621 & 0.325 & -0.01 & - & - & - & - \\
\hline & & 567.602 & 0.340 & -0.01 & - & - & - & - \\
\hline & & 566.664 & 0.375 & -0.01 & - & - & - & - \\
\hline & ${ }^{3} \mathrm{P}^{0}-{ }^{3} \mathrm{P}$ & 463.054 & 0.250 & 0.02 & - & - & - & - \\
\hline & & 464.309 & 0.260 & 0.06 & - & - & - & - \\
\hline & $\begin{array}{c}{ }^{1} \mathrm{P}^{0}-{ }^{1} \mathrm{D} \\
(12)\end{array}$ & 399.500 & 0.270 & 0.06 & 0.60 & 0.56 & 0.60 & 1.01 \\
\hline $\begin{array}{l}2 \mathrm{p} 3 \mathrm{p}- \\
2 \mathrm{p}\left({ }^{2} \mathrm{P}^{0}\right) 3 \mathrm{~d}\end{array}$ & $\begin{array}{c}{ }^{3} \mathrm{P}-{ }^{3} \mathrm{D}^{0} \\
(28)\end{array}$ & 594.167 & 0.260 & - & - & - & - & - \\
\hline \multicolumn{9}{|l|}{ NIII } \\
\hline$\overline{2 \mathrm{~s} 2 \mathrm{p}} 3 \mathrm{~s}-$ & ${ }^{4} \mathrm{P}^{0}-{ }^{4} \mathrm{D}$ & 451.092 & 0.180 & -0.01 & 0.45 & 0.64 & 0.78 & 0.93 \\
\hline $2 \mathrm{~s} 2 \mathrm{p}\left({ }^{3} \mathrm{P}^{0}\right) 3 \mathrm{p}$ & (3) & 451.489 & 0.230 & -0.01 & 0.59 & 0.75 & 0.91 & 1.09 \\
\hline \multirow{5}{*}{$\begin{array}{l}2 \mathrm{~s} 2 \mathrm{p} 3 \mathrm{p}- \\
2 \mathrm{~s} 2 \mathrm{p}\left({ }^{3} \mathrm{P}^{0}\right) 3 \mathrm{~d}\end{array}$} & ${ }^{2} \mathrm{P}-{ }^{2} \mathrm{D}^{0}$ & 393.852 & 0.170 & -0.03 & - & - & - & - \\
\hline & ${ }^{4} \mathrm{D}-{ }^{4} \mathrm{~F}^{0}$ & 486.718 & 0.260 & -0.02 & 0.59 & 0.70 & 0.79 & 1.14 \\
\hline & (9) & 486.133 & 0.290 & -0.02 & 0.66 & 0.78 & 0.88 & 1.27 \\
\hline & $\begin{array}{c}{ }^{4} \mathrm{~S}-{ }^{4} \mathrm{P}^{0} \\
(13)\end{array}$ & 454.636 & 0.255 & -0.05 & - & - & - & - \\
\hline & $\begin{array}{c}{ }^{2} \mathrm{P}-{ }^{2} \mathrm{P}^{0} \\
(\mathrm{UV} 25)\end{array}$ & 298.358 & 0.200 & -0.01 & - & - & - & - \\
\hline \multicolumn{9}{|l|}{ NIV } \\
\hline$\overline{2 \mathrm{~s} 3 \mathrm{~s}}-$ & ${ }^{3} \mathrm{~S}-{ }^{3} \mathrm{P}^{0}$ & 347.869 & 0.205 & 0.01 & - & 1.29 & 1.75 & 1.55 \\
\hline \multirow[t]{3}{*}{$2 s\left({ }^{2} \mathrm{~S}\right) 3 \mathrm{p}$} & (1) & 348.298 & 0.165 & 0.01 & - & 1.03 & 1.39 & 1.23 \\
\hline & & 348.490 & 0.200 & 0.01 & - & 1.26 & 1.72 & 1.52 \\
\hline & ${ }^{1} \mathrm{P}^{0}-{ }^{1} \mathrm{D}$ & 374.766 & 0.250 & 0.03 & - & - & - & - \\
\hline $\begin{array}{l}2 \mathrm{~s} 3 \mathrm{p}- \\
2 \mathrm{~s}\left({ }^{2} \mathrm{~S}\right) 3 \mathrm{~d}\end{array}$ & ${ }^{1} \mathrm{P}^{0}-{ }^{1} \mathrm{D}$ & 405.780 & 0.205 & 0.07 & 0.64 & 0.94 & 1.31 & 1.31 \\
\hline
\end{tabular}

initiated by Dimitrijević \& Konjević (1980, 1981a,b) for the investigated NII, NIII and NIV spectral lines. Griem's (1974) theoretical results for several NII spectral lines are given up to $40000 \mathrm{~K}$ electron temperature. Therefore, the comparison of our measured Stark widths of relevant NII spectral lines with Griem's (1974) theory, at our electron temperature of $54000 \mathrm{~K}$, is omitted. Thus, $w_{\mathrm{SE}}$ and $w_{\text {SEM }}$ denote results of the semi-empirical and modified semiempirical predictions using Eqs. (4)-(5) and Eqs. (7)(10), respectively, from Dimitrijević \& Konjević (1980, 1981a). $w_{\mathrm{G}}$ and $w_{\mathrm{GM}}$ denote values obtained on the basis of the semiclassical approximation (Griem 1974 and references therein) with 1.4 instead of $5-(4.5 / Z)$ on the righthand-side of Eq. (12) in Dimitrijević \& Konjević (1980) for the $w_{\mathrm{GM}}$ values. $w_{\mathrm{SC}}$ denote Stark HWHM calculated on the basis of the semiclassical theory by Dimitrijević \& Konjević (1981b). For the investigated spectral lines no theoretical Stark shift predictions exist at $54000 \mathrm{~K}$ electron temperature, to the knowledge of the authors. 


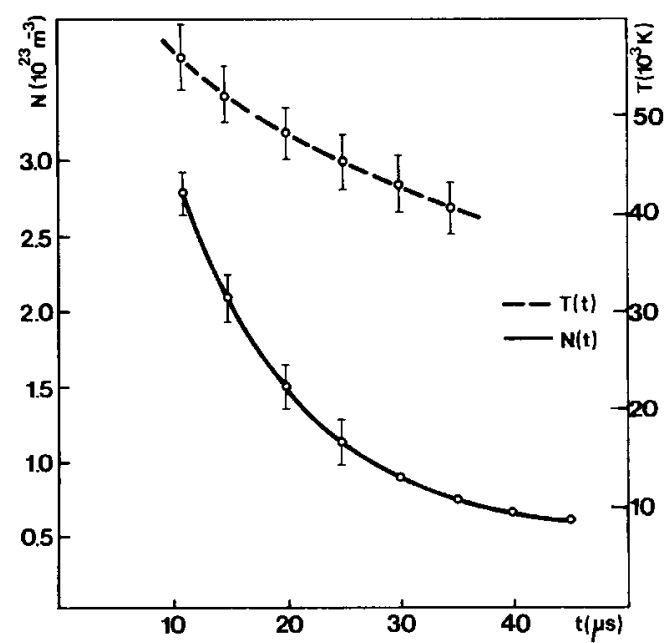

Fig. 2. Temporal evolution of the electron density $(N)$ and temperature $(T)$ in the decaying plasma.

\section{Discussion}

The theoretical Stark HWHM dependence on the electron temperature together with the values of the other authors and our experimental results at the electron density of $N=110^{23} \mathrm{~m}^{-3}$ are presented graphically in Figs. 3, 4 and 5, assuming the domination of the electron impact mechanism to the line broadening, for the investigated NII, NIII and NIV spectral lines, respectively.

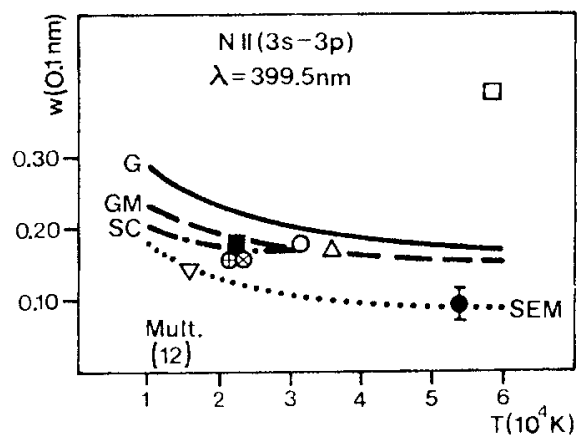

Fig. 3. Theoretical Stark HWHM dependence on the electron temperature scaled to the electron density of $110^{23} \mathrm{~m}^{-3}$ for the NII spectral lines. •, our experimental results and those of the other authors: $\mathbf{\square}$, Berg et al. (1967); $\nabla$, Konjević et al. (1970); ®, Jalufka \& Craig (1975); ๑, Popović et al. (1975); $\square$, Källne et al. (1979); $\triangle$, Purcell \& Barnard (1984) and o, Djeniže et al. (1992). SC, G and GM denote values obtained on the basis of the semiclassical (Griem 1974) approximation, but SEM and SE denote values obtained on the basis of the modified semiempirical and semiempirical approximations, respectively. All these calculations were performed by Dimitrijević \& Konjević $(1980,1981 \mathrm{a}, \mathrm{b}) \cdot \bar{\lambda}$ is the mean wavelength for the multiplet. The error bars include the uncertainties of the width and electron density measurements

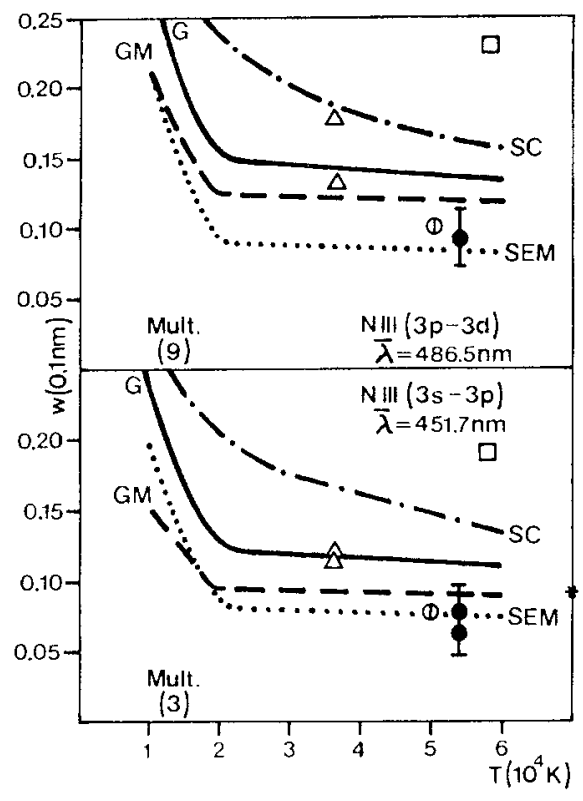

Fig. 4. Theoretical Stark HWHM dependence on the electron temperature scaled to the electron density of $110^{23} \mathrm{~m}^{-3}$ for the NIII spectral lines. The symbols are the same as in Fig. 3; in addition $($, Purić et al. (1987) and *, Glenzer et al. (1994) at approximately $100000 \mathrm{~K}$ electron temperature

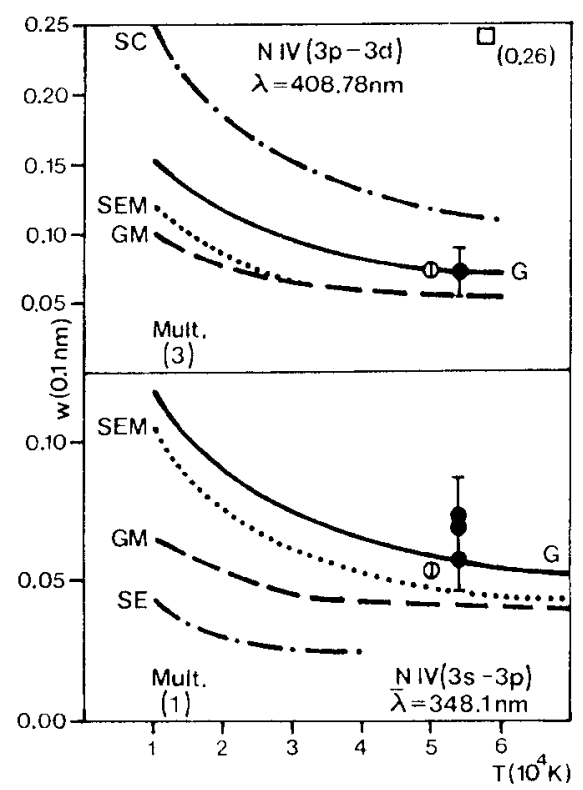

Fig. 5. Theoretical Stark HWHM dependence on the electron temperature scaled to the electron density of $110^{23} \mathrm{~m}^{-3}$ for the NIV spectral lines. The symbols are the same as in Fig. 3; in addition $\mathbb{1}$, Purić et al. (1987)

On the basis of the $w_{\mathrm{m}} / w_{\mathrm{th}}$ values from the Table 1 and Figs. 3, 4 and 5 we can conclude that in the cases of 
the investigated NII and NIII spectral lines our experimental Stark HWHM values well agree, within the experimental accuracy and the reliability of theory, with the value calculated on the basis of the modified semiempirical (SEM) approximation. For the NIV spectral lines this statement can be applied, also, but for the theoretical values calculated on the basis of the semiclassical $(G)$ approximation. It should be pointed out that the Stark HWHM data measured by Glenzer et al. (1994) (at approximately $100000 \mathrm{~K}$ electron temperature and $110^{23} \mathrm{~m}^{-3}$ electron density it is $0.0093 \mathrm{~nm}$ ) and Purić et al. (1987) shows, for the multiplet No. 3 in NIII spectra, agreement with the predictions based on the SEM approximation, within the experimental accuracy.

No calculated Stark HWHM values exist for the spectral lines, at electron temperatures higher than $40000 \mathrm{~K}$, from the multiplets Nos. 3, 5 and 28 in NII spectra, Nos. 8, 13 and UV25 in NIII spectra and No. 8 in NIV spectra, to the knowledge of the authors. Therefore, the comparison of our Stark HWHM data of relevant spectral lines with theory is omitted.

In the case of the Stark shifts the situation is different. Namely, the measured values $d_{\mathrm{m}}$, normalized to an $110^{23} \mathrm{~m}^{-3}$ electron density, are generally very small, within experimental error $( \pm 0.0015 \mathrm{~nm})$ they are close to zero. Early measurements of the Stark shift values for the NIII spectral lines (Purić et al. 1988) and for the NII spectral lines (Djeniže et al. 1992) referee, also, very small Stark shift values. No calculated Stark shift values exist for the investigated NIV spectral lines, therefore, the comparison there with our measured values is omitted.

\section{References}

Ashby D.E.T.F, Jephcott D.F., Malein A., Ragnev F.A., 1965, Appl. Phys. 36, 29

Berg H.F., Ervens W., Furch B., 1967, Z. Phys. 206, 309

Davies J.T., Vaughan J.M., 1963, Aph. J. 137, 1302
Dimitrijević M.S., Konjević N., 1980, JQSRT 24, 451

Dimitrijević M.S., Konjević N., 1981a, "Spectral Line Shapes" Wende B. (ed.). Berlin, de Gruyter, p. 211

Dimitrijević M.S., Konjević N., 1981b, JQSRT 25, 387

Djeniže S., Srećković A., Labat J., Konjević R., Popović L., 1991, Phys. Rev. A44, 410

Djeniže S., Srećković A., Labat J., 1992, A\&A 253, 632

Fuhr J.R., Lesage A., 1993, "Bibliography on Atomic Line Shapes and Shifts", July 1978 through March 1992, NIST Special Publication, Supplement 4 US: DC National Institute of Standards and Technology p. 366

Glenzer S., Hey J.D., Kunze H.J., 1994, J. Phys. B27, 413

Griem H.R., 1974, "Spectral Line Broadening by Plasmas". New York: Academic Press

Jalufka N.W., Craig J.P., 1970, Phys. Rev. A1, 221

Källne E., Jones L.A., Barnard A.J., 1979, JQSRT 22, 589

Konjević N., Mitrović V., Ćirković Lj., Labat J., 1970, Fizika 2,129

Konjević N., Wiese W.L., 1976, J. Phys. Chem. Ref. Data 5, No. 2

Konjević N., Dimitrijević M.S., Wiese L., 1984, J. Phys. Chem. Ref. Data 13, No. 3

Konjević N., Wiese W.L., 1990, J. Phys. Chem. Ref. Data 19, 1324

Milosavljević V., 1996, Mast. Th. Belgrade, Faculty of Physics (unpublished)

Popović M., Platiša M., Konjević N., 1975, A\&A 41, 463

Popović L., Srećković A., Djeniže S., 1992, Proc. the $11^{\text {th }}$ ICSLS, A25, Carry le Rouet

Purcell S.T., Barnard A.J., 1984, JQSRT 32, 205

Purić J., Konjević N., 1972, Z. Phys. 249, 440

Purić J., Srećković A., Djeniže S., Platiša M., 1987, Phys. Rev. A36, 3957

Purić J., Djeniže S., Srećković A., Milosavljević M., Platiša M., Labat J., 1988, Proc. the $14^{\text {th }}$ SPIG, 345, Sarajevo, Yugoslavia

Wiese W.L., Smith M.W., Glennon B.M., 1966, "Atomic Transition Probabilities" NSRDS NBS 4 Vol. 1, Washington, DC: US Govt Printing Office 